\title{
INNOVATIVE APPROACHES IN TEACHING FOREIGN LANGUAGES METHODOLOGY
}

\author{
Yuldasheva Dilshoda Musaevna PhD \\ Samarkand State University, Uzbekistan
}

\begin{abstract}
This paper discusses one of the creative approaches to teaching foreign Languages for Special Purposes (LSP). Moreover, there are given some examples of teaching methodology in the process of conducting foreign languages classes based on experience of several researchers including Russian academician L.V. Shcherba. Besides, the article describes the detailed characteristic of innovative practices for the English language classroom.
\end{abstract}

Key words: methods of teaching foreign languages, innovation, teaching, multimedia, E-portfolio, communicative approach.

Cite this Article: Yuldasheva Dilshoda Musaevna, Innovative Approaches in Teaching Foreign Languages Methodology, International Journal of Management, 11(12), 2020, pp 87-91.

http://iaeme.com/Home/issue/IJM?Volume=11\&Issue=12

\section{INTRODUCTION}

Methods of teaching foreign languages did not disappear with the advent of new ones: there was a kind of imposition of one method on another, a new one on old or old on new. In a broad sense it can be noted that there is no clear border between the various methods, there is their eclectic mixing. Therefore, the methods should be considered as part of a paradigm (a unit of theory and practice) that suggests the main way of constructing theories and conducting scientific research. The methods of teaching foreign languages have arisen in response to the emergence of new theoretical data. They are determined by both the philosophy of education and nature. Language, imbued with social values. The change of these determinants was a change of the model.

Within the framework of this approach, the idea of language as a structure or model is formed. Knowledge through skill formation. A structured approach to teaching foreign languages is based on the provisions of structural linguistics and behaviorism in psychology. Learning involves mastering a range of grammatical structures-samples, which are arranged in a certain sequence depending on the difficulty of their assimilation [1]. 
Initially, all methods of teaching foreign languages were borrowed from programs designed to teach "dead languages" - Latin and Greek, within which almost the entire educational process was reduced to reading and translation. This method was laid down by the enlighteners. Back at the end of the 18th century under the name "Grammar translational method" (grammar-translation method, in the west known as the Prussian method). Representatives of this method are W. Humboldt, D. Hamilton, G. Ollendorf, J. Jacotto, Ch. Toussaint and others. The popularity of the method was explained, on the one hand, its relevance to educational goals that were put before students of foreign languages, and with the other - by traditions inherited from the methodology teaching Latin in the Renaissance. The goal of learning a foreign language for a long period of time was considered a common education of students, the development of logical thinking as a result of translation of texts and execution grammatical exercises. The learner must understand the grammatical structure of foreign language by comparing with the native language, consistently reconstruct the grammatical and lexical system of a foreign language and reproduce correct sentences, applying rules [2]. Subsequently, learner must be able to retell or learn by heart texts, write essays, give definitions to lexical units. Thus, the grammar-translation method is oriented on the formation of students in the first place linguistic language competence to the detriment of speech competence.

The oral method originated in the British applied linguistics in the 1920s and 1930s and represented by the works of G. Palmer and A. Hornsby. This approach was the first attempt to scientifically substantiate the teaching of foreign languages. Due to the special attention to the situational representation and use of language in the 60s of the XX century, this method became called situational. The main goal is oral training of sentence models in situations, which gives learners a tremendous speech practice. Particular attention is paid to the meaning of the sentences. Among the characteristic features of the situational method are the following:

a) the program is structured according to models proposals in a phased sequence;

b) vocabulary is considered an important component in teaching foreign languages;

c) the teacher creates a situation and teaches by interviewing students;

d) it is assumed that students must guess the meaning of the word from the context without translation or explanations in your native language;

e) grammatical structures are studied in the stream speech through repetition, substitution, reading aloud;

f) grammar is studied inductively, in contrast to deductive grammar-translation technique from simple forms to more complex ones;

g) correct pronunciation and observance great importance is attached to grammar rules;

h) the importance of oral communication prevails over writing

Paul Gunasekar, professor at the University of English and Foreign Languages (Hyderabad, India) points out that "innovation can cover a very wide range of areas, some of which include ways to systematically assess student knowledge, improve teacher training, innovative classroom practices including new technologies, additional instruction for students, methods of increasing the motivation of teachers, their effectiveness, mobilizing resources from third parties to improve the quality of education "[3].

Today, the role of the teacher as a carrier of information and organizer of educational activity is gradually transformed into the role of an intermediary 
Innovative changes in the modern educational process are associated with information communicative aspect, which is aimed at ensuring interaction in the process of general human activity.

In order to prove this statement, let us study the example given in the Investigator Chris Davison from Hong Kong. The scientist proposes the project "Virtu-social connections: the audience as a place for intercultural learning ", the purpose is to include in a real situation communication between students from different countries by email. The project described by Chris Davison was sufficiently successful, given the expediently certain "virtual training" triangle from two groups in Germany and the third from Canada. Success of this project can be explained by the fact that one angle "virtual triangle" enters an authentic language environment.

The emergence of information communication technology has significantly expanded the range of opportunities for involving native speakers in the learning process, and without leaving them a authentic language environment. About the boundaries of the classroom, the researcher notes: if we take into account the fact that, if desired, it is easier to find language speakers who are in the natural language environment for interaction, then students in the learning process can virtually go not only outside the classroom, university, local community, but also a country or even a continent. Attention should be paid to the practice of using electronic portfolios together one hundred paper papers in the study of foreign languages, proposed by Ananya Tuksin and Richard Watson Todd. Scientists argue that the advantage eportfolios are obvious - ease of access:

- after all, you only need enable multimedia projects and provide effective feedback from students. The functions of this innovative technology are as follows:

- direct contact of the student with the teacher through a convenient web a page that outlines a practical learning plan for achieving certain divided goals within a specified time;

- involvement of students in decision-making of assigned tasks makes training reading relevant;

- mechanism provides students with external links to learn new lectures, grammar; a link on the website lists the best student profiles that motivate teach other participants and give them the opportunity to learn from a bright example [5].

Interactive methods provide the mechanisms to enable group members to explore, on a regular basis, the reasons they are doing their work and why it is important. They provide people with opportunities to consider and share the experiences, understandings, and commitments that brought them to the group. Being in touch with these fundamental elements is critically important if group members are to be invested in the group's work and motivated to make difficult decisions, resolve disagreements, and apply energy and focus to their work. Interactive techniques can be used to help a group define its own dynamics and its own problems - the first step in moving through the issues and toward the group's goals. When tension between people, general stress, or individuals' personal issues or behaviors are impeding a group's functioning, these can be dealt with most effectively when the group itself, rather than the leader, articulates the problems. Interactive techniques can be used to help a group define its own dynamics and its own problems - the first step in moving through the issues and toward the group's goals.

The most important for modern methodology in the works of L.V. Shcherba is a substantiation of a communicative approach to teaching foreign languages. The communicative approach in the methodology is determined by the very essence of speech communication as the process of communication:"... although the individual process of 
speaking and understanding themselves are purely biological ( to some extent psychological ) they become a language only in the conditions of their social life and therefore language should be considered as a social phenomenon. This social nature of language is reflected primarily in the unity of the processes of speaking and the processes of understanding, constituting a single whole the process of communication.

L. V. Shcherba points out the need to take into account all three aspects of linguistic phenomena in educational materials, with the leading role of the aspect of the individual's speech activity in the communication process. In teaching, ready-made units (word forms, combinations of words and ready-made phrases) are mastered first of all, which are distinguished and observed in direct speech experience. However, a person's linguistic experience consists not only in the simple repetition of ready-made phrases, but also in the compilation of new phrases in accordance with the communication situation.

Innovations in methodology used in the educational process of higher institutions are connected with the use of new technologies. Interactive training as a new methodological approach to the foreign language teaching gives a chance to solve communicative-cognitive tasks through foreign language communication. So, in terms of methodology, the meaning of a category interactive training will be considered as:

a) a dialogue training in the course of which interaction between a teacher and a student occurs;

b) training the purpose of which tackles linguistic, communicative and action tasks. Interactive training activity involves the organization and development of dialogue speech aimed at mutual understanding, interaction, solving of innovative and general but significant tasks for every participant of the educational process.

So, innovative methods of teaching English language give us a chance to solve some problems simultaneously. The main purpose is to develop communicative skills, cheap establish emotional contact with the students, provide with realization of educational task, that is: to train them to work in a team, to consider somebody's opinion. As seen from experience the use of the above mentioned methods helps to avoid a student's nervous tension, to change the forms of activity, to draw attention to the main questions of the lesson.

To summarize the innovative methods of teaching give the foreign language teachers the possibility to master some new techniques of communicative methods of foreign language training. Risk taking and conversational interaction play a major part in language acquisition. It is hoped that this brief survey will encourage many language teachers to learn more about the innovative methods of training. Such, knowledge will give some healthy, perspective in evaluating the innovations of new approaches to methodology that will continue to emerge over time.

\section{CONCLUSION}

Teaching methodology in the process of conducting foreign languages classes based on experience of several researchers including Russian academician L.V. Shcherba. Besides, the article describes the detailed characteristic of innovative practices for the English language classroom 


\section{REFERENCES}

[1] Kashina E.G. Traditions and innovations in methods of teaching a foreign language: textbook. manual for students of philological departments of universities. Samara: Publishing house "University-Group", 2006. P 75.

[2] L.V. Shcherba. Teaching foreign languages in secondary school. General questions of the methodology. L.V. Shcherba M., 1947. Pages 96-97

[3] Innovation in English Language Teacher Education. Edited by George Pickering and Professor Paul Gunashekar. India, 2014. P. 290.

[4] Innovation in English Language Teacher Education. Edited by George Pickering and Professor Paul Gunashekar. India, 2014. 290 p.

[5] Tuksin A., Todd R. W. The E-pet: Enhancing motivation in E-portfolios. English Teaching Forum Online, 2009. Available at: http://exchanges.state.gov/englishteaching/ forum/archives.html

[6] L.V. Shcherba "Teaching foreign languages in secondary school. General questions of the methodology”. L.V. Shcherba M., 1947. 96-97 pages

[7] L.V. Shcherba "On the relationship between native and foreign languages. - Foreign languages at school” 1934 p. 95 No. 1 